\title{
Challenging discourses of aspiration: the role of expectations and attainment in access to higher education
}

\author{
Neil Harrison and Richard Waller \\ University of the West of England
}

\begin{abstract}
Raising the proportion of young people from disadvantaged backgrounds progressing to higher education has been a key policy objective for successive governments in the United Kingdom since the late 1990s. Often this has been conceptualised as a problem with their 'aspirations', with the solution being seen as the provision of 'aspiration-raising' activities to promote higher education to those thought to have the potential to progress. Recent large-scale studies cast strong doubt on this hypothesis by demonstrating that aspirations are not generally low, that different social groups have similar levels of aspiration and that school attainment accounts for nearly all the differences in participation rates between different social groups.

This paper draws on data from a national project exploring efforts to widen participation across two generations of practitioner-managers in England, focusing on their conceptualisations of the field and their constructions of 'successful' activities. It uses the lens of 'possible lives' (Markus \& Nurius, 1986) to argue that too much policy emphasis has been placed on the aspirations of young people, rather than either their academic attainment or their expectations, which are shaped by the normative expectations of the adults surrounding them. In addition, the more expansive concepts of widening participation that were present a decade ago have become less common with a shift towards activities with a clear role in institutional recruitment rather than social transformation. The paper concludes with alternative suggestions for policy and practice.
\end{abstract}


Despite nearly twenty years of concerted policy attention and significant funding streams, stark differences remain in the proportions of young people from different socioeconomic groups who progress to higher education (HE) in the UK. The latest official figures show that 24 percent of those from low-income households progressed, compared to 41 percent from mid- and highincome households (Department for Education [DfE], 2017). There has been clear progress over the last decade - the equivalent figures for 2005/06 were 13 and 33 percent respectively - but the inequalities remain striking, with 'the highest socio-economic quintile group [being] around 3 times more likely to go to university and around 7 times more likely to go to a selective institution than those from the lowest socio-economic quintile group' (Crawford and Greaves, 2015, p.9). The recent White Paper reasserts the longstanding policy aim to close this gap, setting out 'to double the proportion of people from disadvantaged backgrounds entering university in 2020 compared to 2009' (DfE, 2016, p.54), while ensuring a more equitable distribution of places at highly-selective universities.

This policy has its roots in the Dearing Review (National Committee of Inquiry into Higher Education, 1997), which first detailed the social differences in HE participation and laid the groundwork for a series of policy documents that would establish what become known as the 'widening participation' agenda (Department for Education and Employment [DfEE], 2000; Department for Education and Skills [DfES], 2003a,b; Higher Education Funding Council for England [HEFCE], 2004, 2005).

These early documents heavily emphasise the need to 'raise aspirations' for HE among disadvantaged young people, situating the problem - at least in part - with the young people and their families. For example, the 2003 White Paper (DfES, 2003a, p.69) argues that

'It is especially important that those who come from families without a tradition of going to $\mathrm{HE}$, and whose aspirations are low, are supported both in achieving their full potential before university, and in aspiring to go on to further study.'

This deficit discourse was critiqued from an early stage, with Leathwood and O'Connell (2003), Jones and Thomas (2005), Archer (2007) and others arguing that it failed to locate educational choices within longstanding social structures and absolved universities and schools from responsibility for changing. However, in policy terms, it still persisted into the 2010 Schools White Paper, which asserted that 'in far too many communities there is a deeply embedded culture of low aspiration that is strongly tied to long-term unemployment' (DfE, 2010, p.4). While the rhetoric has softened, the word 'aspiration' appears twenty-three times in the latest widening participation strategy (Department for Business, Innovation and Skills [BIS], 2014).

The policy aim to widen participation has thus been inexorably linked to the discourse of aspirations for nearly twenty years, albeit that the term tends to be rather loosely used. The 2003 White Paper (DfES, 2003a, p.5) defines 'aspiration' in a narrow and functional sense as being 'the desire to enter higher education and realise personal potential through gaining a higher education qualification', whereas it is often used within the sector to encompass a wider, but vaguer, sense of seeking to improve one's life chances and confidence in education as a means to do so (e.g. DfE, 2010). We will come on to discuss this looseness of definition and application later. 
We also aim to add to earlier critiques by reviewing recent studies that question the assumed relationship between young people's reported aspirations for $\mathrm{HE}$ and their socio-economic status, their school attainment and their future participation in HE. Rather, the literature suggests that young people from different social groups have similar aspirations, but that their expectations around HE may have a stronger relationship with participation as they reflect subjective assessments of probability, influenced by personal experience and the expectations of the adults surrounding them. The paper situates this discussion within the work of Markus \& Nurius (1986) on 'possible selves', which provides a theoretical lens for examining the interplay between an individual's contrasting desires for the future and their relative likelihoods.

Finally, we draw on empirical data from a wider research project undertaken to explore the construction of 'success' among two generations of practitioner-managers working to widen participation in $\mathrm{HE}$ in England; the first drawn from the Aimhigher programme of the late 2000s and the second from the post-Aimhigher era of the mid 2010s. This paper addresses the following research questions:

1. In what ways did/do practitioner-managers conceptualise their work with respect to aspirations, expectations and attainment?

2. What similarities and differences exist between the two generations of practitionermanagers and how is this reflected in their practices?

3. What are the implications for future policy and practice?

We find that while there are diverse voices within the two groups of practitioner-managers, the majority are more comfortable conceptualising their work in terms of aspirations and that this impacts on what outreach activities are offered. We conclude by rejecting the discourse of aspiration-raising and argues that young people's expectations and attainment are more appropriate targets for policy intervention.

\section{Policy context}

Widening participation among disadvantaged young people took form as a policy agenda in the early 2000s, although many activities had their origins some time earlier (Woodrow et al., 1998). The Excellence Challenge (DFEE, 2000, p.1) announced funding, inter alia, to 'recruit more admissions staff, send ambassadors to schools and colleges and to run more open days and summer schools for young people and their teachers'. This portfolio of what have become known as 'outreach' activities continues to form a core element of widening participation work; it is also the focus of this paper. Ambassadors visiting schools have been supplemented by a range of mentors (providing positive role models) and tutors (helping with schoolwork), while targeted open days have become known as 'taster days', providing authentic on-campus experiences; summer schools comprise a longer period, generally with overnight stays. The main additions have been the provision of academic enhancement activities (e.g. 'masterclasses' in schools run by university staff) and structured intervention programmes with local schools spanning several years. Moore \& Dunworth (2011) provide a useful overview of activities developed since 2000.

The Excellence Challenge (DFEE, 2000) also created a framework and funding for new partnerships between institutions, further education colleges and schools. In England, this would morph into the national Aimhigher programme (DfES, 2003a,b; HEFCE, 2004). With nine regional organisations, over forty sub-regional partnerships and a national coordinating function, 
Aimhigher was the government's flagship widening participation 'brand' from 2004 to 2011; funding was reduced in 2008 before abolition three years later under successive governments' austerity programmes. Aimhigher seeded cooperation and collaboration between institutional efforts, especially with the aim of reaching areas and social groups that had not previously been engaged. Because of the diversity of activity and difficulties with data collection, it was problematic to demonstrate the success of Aimhigher's work, although assessments have generally been positive (e.g. Chilosi et al., 2013; Doyle \& Griffin, 2012; Harrison, 2012). The first set of data reported in this paper is drawn from practitioner-managers active during this period; specifically, those charged with managing the regional and national Aimhigher elements.

In parallel with Aimhigher, institutions were expected to provide a growing portfolio of outreach activities. Funding originally announced in DFEE (2000) essentially continues - now branded as the Student Opportunities Fund - and since 2006 has been supplemented by monies derived from student tuition fees. Under regulation from the Office for Fair Access (OFFA), institutions wishing to charge above a fee threshold (currently $£ 6,000$ a year) are required to dedicate a negotiated portion of their income to outreach activities. The total spent in 2014/15 was $£ 174.5$ million, up from $£ 97.1$ million when Aimhigher was disbanded (OFFA, 2016). In common with the direct costs of $\mathrm{HE}$ being shifted from the state to individual students, an increasing proportion of outreach work is now indirectly funded by current students through their fees. The second set of data reported in this paper is drawn from practitioner-managers active during this period; specifically, those managing institutional operations after the end of Aimhigher.

More recently, two national initiatives have sought to re-establish elements of the cooperative ethos that characterised the Aimhigher period. The National Networks for Collaborative Outreach (NNCOs) were announced in 2014 with two-year funding aimed at seeding partnership working between institutions within discrete geographical areas or with respect to distinct social groups (HEFCE, 2014). The National Collaborative Outreach Programme (NCOP) is similarly based around local partnerships with two years of funding (HEFCE, 2016), but tightly targeted at neighbourhoods where $\mathrm{HE}$ participation rates are lower than predicted by school attainment. These two programmes post-date the study presented in this paper, but are included for completeness.

\section{Theoretical lens}

The English word 'aspire' is drawn from Latin meaning 'to breathe', with the implication of giving life to an idea; the Oxford English Dictionary associates it with 'desire, longing, or ambition' as well as to 'soar and reach up'. Crucially, an aspiration is contextualised; it is a positive future state that is sought. With this in mind, we draw here on the theoretical lens of 'possible selves' introduced by Markus \& Nurius (1986) as part of wider theoretical work on self-concept, which argues that a powerful force in decision-making is the ability to conceptualise future possible identities, situations or ways of being:

'An individual is free to create any variety of possible selves, yet the pool of possible selves derives from the categories made salient by the individual's particular sociocultural and historical context and from the models, images, and symbols provided by the media and by the individual's immediate social experiences. Possible selves thus have the potential to reveal the inventive and constructive nature of the self but they also reflect the extent to which the self is socially determined and constrained' (p.954). 
People have a unique palette of possible selves, being subject to different values and societal norms that determine their desirability. Within the pool of possible selves, Markus \& Nurius (1986, p.966) distinguish between 'like-to-be' and 'probable' future selves, exercised through the 'individual's conception of probability'. These are broadly analogous to the ideas of aspiration and expectation - there is an important distinction between what selves a young person might desire and those they think likely.

Importantly, Markus and Nurius view possible selves as part of a working concept of self that is constantly in flux, responding reflexively to accumulated personal experiences, social encounters and the wider sociocultural context. A key concept is that of 'elaboration' which denotes the extent to which a possible self is fully-formed in the mind of the individual - whether it is a vague sketch or a detailed portrait. It also encapsulates the nature of their plan, if any, for achieving the possible self. The individual's palette of possible, probable and like-to-be selves is therefore open to change and greater elaboration, with scope for planned interventions to achieve this.

Drawing on their pool of possible selves, the individual is then able to choose current actions that either work towards a desirable future self (e.g. in a graduate job) or the avoidance of an undesirable one (e.g. being unemployed); 'cognitive bridges between the present and the future' (Markus \& Nurius, 1987, p.159). In particular, it is argued that the existence of a well-elaborated like-to-be self has a motivational effect, both stimulating concerted action and legitimising and giving meaning to that action (Markus \& Ruvolo, 1989; Leondari, 2007). This is hypothesised to be particularly strong where a like-to-be self is aligned with a probable self, providing a conceptual link between future expectations and current engagement with school:

'The more compelling the possible self, the more vividly it can be elaborated in the present, and the more it will command attention and structure one's current activity' (Markus \& Ruvolo, 1989, p.229).

While the theory of possible selves has enjoyed significant impact in psychology, especially around career planning and youth transitions (e.g. Hardgrove et al., 2015), its empirical application to issues of school attainment has been limited to date. Leondari et al. (1998) found that young people with highly-elaborated possible selves were more persistent and attained more highly than others. They were also more likely to see achievement of their like-to-be self as being the result of hard work rather than luck. Oyserman et al. (2002) and Oyserman et al. (2007) reported on interventions based on developing stronger possible selves that helped to seed stronger school engagement and to ameliorate the negative effects of parental disengagement on a young person's learning. The theory has recently gained traction with respect to participation in $\mathrm{HE}$ (Harrison, forthcoming; Henderson et al., forthcoming) and transition to the graduate labour market (Stevenson \& Clegg, 2011; Papafilippou \& Bentley, 2017).

While it has its roots in psychology, the relationship to wider sociocultural contexts affords the idea of possible selves a broader relevance to social science, with clear resonances with betterknown theoretical concepts such as reflexivity (Archer, 2007), the project of the self (Giddens, 1991), habitus (Bourdieu, 1984) and accessibility (Kahneman, 2003).

It also resonates with work on young people's careers by Hodkinson \& Sparkes $(1993,1997)$ who use the metaphor of vision to define 'horizons for action' - an assessment of the 'distance' that an individual can 'see', framing 'the arena within which actions can be taken and decisions made' (Hodkinson \& Sparkes, 1997, p.34). They argue that these horizons are influenced by a range of 
social structures delimiting what appears possible, desirable or socially appropriate. For some young people, the advantages conferred through their family means that the horizon is distant, with a wide range of desirable options available, freedom to act and an assumption of achievability. However, for disadvantaged young people, they are much closer and contingent fewer options subjectively seem (or objectively are) possible.

Raphael Reed et al.'s (2007, p.14) examination of four urban communities with very low HE participation where 'many young people grow up in environments where they rarely encounter educational or economic success - or the relationship between the two' found they were shaped by longstanding perceptions about how the education system and labour market worked:

'Intersecting with their experiences within family and community contexts we begin to see how relatively restricted 'horizons for action' are shaped and reinforced over time. Whilst individual young people are able to resist the inscription of such learning identities and to 'escape' foreshadowed learning trajectories, this has only been possible for the determined few' (pp.49-50).

Horizons for action help us to understand the construction and elaboration of possible selves. They describe how perceptions of 'the possible' are shaped by family history and prevailing structural constraints in a young person's community. These, in turn, influence (and delimit) the palette of conceivable possible selves and the assessment of which are considered to be desirable (i.e. aspiration) or probable (i.e. expectation); these can then motivate and/or legitimise current actions.

\section{Literature review}

\section{Aspirations and socioeconomic status}

An assumption that low aspirations undermine the demand for $\mathrm{HE}$, especially for disadvantaged young people, has a long history; however, evidence for this is scant. Indeed, there has been a growing consensus from empirical studies that rather than being low, young people's aspirations (in this sense of a reported desire) for both HE and future careers are high - and higher than the realistic opportunities available to them within the labour market and/or at their likely level of attainment.

For example, Baker et al.'s (2014) study of 1,745 14-year-olds found that 'the vast majority of students, including those from highly disadvantaged backgrounds, hold high aspirations for pursuing further academic qualifications' (p.526); only the very highest income group was an outlier. They conclude that aspirations for $\mathrm{HE}$ are complex and multidimensional, with socioeconomic factors playing only a modest role. Croll \& Attwood's (2013) analysis of data from the Longitudinal Study of Young People in England matched HE aspirations at the age of 14 with outcomes at 20, with higher socioeconomic groups being somewhat more likely to aspire to $\mathrm{HE}$, although others still had aspiration levels that were far in advance of their actual participation rates.

Similarly, Archer et al.'s (2014) study of 12/13-year-olds found high career aspirations, with little difference between socioeconomic groups. The children prioritised jobs offering money and status, as well as opportunities to help others and maintain a work/life balance. Working with 
similarly-aged children in three contrasting schools in disadvantaged neighbourhoods, St. Clair et al. (2013, p.736) also reported high levels of aspirations for both HE and professional careers that were 'well above what the labour market can support [and] it would be problematic to view aspirations as effective and robust leverage points that can be used to change current behaviour and future outcomes'. Aspirations were often significantly beyond what the young person's attainment profile would permit and they lacked knowledge about the qualifications needed for particular careers. Green et al. (in press) concur from their analysis of the 1970 British Cohort Study, concluding that aspirations play a very small part in predicting life outcomes: 'strategies to raise self-esteem, locus of control and aspirations in the state [education] sector are unlikely to be greatly effective'.

\section{Aspirations and attainment}

Meanwhile, evidence for a link between aspirations and future attainment is somewhat contradictory, as summarised in a series of focused reviews commissioned by the Joseph Rowntree Foundation. Goodman \& Gregg (2010), drawing on Chowdry et al. (2010), report a strong association between aspirations for $\mathrm{HE}$ and attainment in secondary school, even once controlling for earlier attainment. Higher attainment was also associated with the related concepts of the young person's self-confidence and belief in their own agency or locus of control (Baker et al., 2014; Chevalier et al., 2009; Fuller, 2012). However, Cummings et al.'s (2012, p.4) review of over 60 research reports concluded that:

'There is no easy solution to closing the attainment gap for poorer children by focusing on change in aspirations, locus of control and valuing school. The widespread emphasis on raising aspirations, in particular, does not seem to be a good foundation for policy or practice. Indeed, there were almost no studies that tried to test the hypothesis that attitude change leads to impact on attainment, in spite of its widespread acceptance'.

They did find some evidence for the effectiveness of interventions around increasing parental involvement in young people's education, mentoring schemes and extra-curricular opportunities, conceding there might be some aspirational element within these. Potentially squaring-off this contradiction through their review, Gorard et al. (2012) agreed there was an association between aspirations and attainment, but concluded that it was unclear that it was causal and that it most likely ran in the opposite direction - i.e. that attainment increases aspirations by making 'higher' options seem achievable. Indeed, school setbacks can lead to a 'cooling out' (Nielsen, 2015) or 'levelling down' (Kintrea et al., 2015) of aspirations. Accordingly, Gorard \& See (2013, p.128) argue 'there is insufficient evidence for a causal link to justify any intervention to raise aspirations in order to raise attainment', while Baker et al. (2014) find 'little evidence to suggest that interventions designed to raise aspirations are likely to be effective in narrowing educational attainment gaps' (pp.539-540).

\section{Attainment and participation}

Work by Crawford (2014) and Crawford \& Greaves (2015) using large national datasets has demonstrated the complexity underlying differential participation in HE. In particular, the direct impact of socioeconomic status is reduced to nearly zero once Key Stage 2 (age 11) and Key Stage 4 (age 16) attainment are taken into account. The latter is particularly important, with each 
additional GCSE grade $A$ or $A^{*}$ increasing participation between 2 and 4 percent, depending on subject and grade. This is not, of course, to say that socioeconomic factors have no impact on decisions to enter $\mathrm{HE}$, but rather that their effect is mediated through earlier attainment. Some of this effect is apparent by the age of 11 (and potentially much earlier), but the majority manifests in the qualifications acquired at the age of 16 .

This is a vital contribution to understanding participation in HE. At the macro level, 16-year-olds will tend to go on to enter $\mathrm{HE}$ at the rate predicted by their qualifications - and to the status of institution predicted. This has been hinted at in previous research (e.g. DfES, 2003b; Coleman \& Bekhradnia, 2010), but this critically questions the logical basis of aspiration-raising. Similarly, Croll \& Attwood $(2013$, p.201) concluded that while there may be some mileage in schools and others seeking to raise aspirations, this is nothing like as important as raising achievement for less advantaged young people' to equalise HE participation rates.

\section{Aspirations vs. expectations}

Expectation, rather than aspiration, potentially offers an alternative paradigm for understanding young people's HE decision-making. While aspirations are rooted in a desirable future state, expectations temper this with an element of achievability - both internalised ('I can achieve this') and externalised ('I will be allowed to achieve this'). Khattab (2015) highlights the limited correlation between aspirations and expectations using a large-scale national dataset, while Boxer et al. (2011) find that disadvantaged young people tend to have considerably higher aspirations than expectations. The process of forming expectations must therefore be cognitively distinct from forming aspirations.

One likely factor in expectation formation is the influence of key adults, including parents and teachers. In Archer et al.'s (2014) study, parental expectations were found to have a socioeconomic dimension, although 47 percent of children in the lowest group still believed their parents wanted them to enter HE. Fuller (2014, p.142), in a qualitative study of a school serving a deprived community, found that aspirations for HE among 14- to 17-year-olds were closely tied to the expectations of parents - especially those with 'a desire to see their daughters achieve where they had not'; Baker et al. (2014) concur. Gorard \& See (2013, p.153) conclude that 'there is considerable evidence that parental expectations are linked to their children's school outcomes', drawing particular attention to mothers.

Winterton \& Irwin (2012) and Fuller (2014) argue that parents of disadvantaged young people are likely to want them to succeed through education, but may not expect them to do so, perhaps based on their own negative experiences or their potentially realistic assessment of a congested youth labour market; they may also have normative expectations that are not predicated on educational attainment. In a related point, while Archer et al. (2014) suggest that parents from different backgrounds are generally supportive of their children's aspirations, those from higher socioeconomic groups are more likely to be able to provide practical advice, role modelling and enrichment activities (also see Kirk et al., 2010 for US evidence), while Cummings et al. (2012) commend activities to increase parental involvement in schooling.

Similarly, there is evidence for the importance of teachers' expectations. For example, Baker et al. (2014) and Fuller $(2012,2014)$ highlight the role of positive links with the school or a supportive teacher, with access to a professional source of encouragement and advice being useful to a 
young person (also see Bathmaker et al., 2016 and Reay et al., 2009). Smyth \& Banks (2012) draw on ideas of institutional habitus within Irish schools to explain differences in the expectations held by teachers (and transmitted to pupils), while Donnelly (2015) suggests the 'hidden curriculum' as a mechanism for the same. Lupton (2005) discusses how teachers in disadvantaged areas struggle to maintain the high expectations that they believe are important, while Rubie-Davies et al. (2015) report on a successful experimental approach in New Zealand.

Winterton \& Irwin's (2012) comparative study of young women from contrasting socioeconomic groups found that those from more advantaged backgrounds received an expectation of progressing to HE from both their parents and their schools, while those from disadvantaged backgrounds were motivated by their growing academic self-confidence or the influence of individual teachers. In terms of interventions, school-based careers advice and work experience were seen as being key for disadvantaged young people, especially as their aspirations required a step out of the family trajectory, rather than the continuation of an intergenerational narrative; 'a move away from the focus on 'high' aspirations towards an emphasis on 'diversifying' and 'informing' aspirations, with appropriate support, to ensure that all young people can find routes to achieve interesting and fulfilling, well-paid jobs' (Winterton \& Irwin, 2012, p.77). Similarly, instead of the 'red herring' of aspiration-raising, St Clair et al. (2013, p.736) advocate improved careers advice, the use of work experience placements and a 'day to day process of supporting students to learn how to attain what they want'.

\section{Summary}

There is growing evidence, therefore, that there is not a 'problem' with young people's aspirations, but rather that they expect to achieve markedly lower outcomes than they desire. In the terms used by Markus \& Nurius (1986), this suggests there is a frequent misalignment between like-to-be and probable selves. Furthermore, the recent literature questions whether aspirations alone can create motivation for higher attainment in school. This is consistent with young people having limited opportunities to elaborate possible selves in ways that enable them to identify clear pathways to achieving like-to-be selves; Markus \& Ruvolo (1989) argue that this process of elaboration is vital in creating motivation and in legitimising current actions towards a future goal. In this case, this relates directly to engagement with school to attain at a level that permits access to HE.

Whereas there appears to be only a modest relationship between young people's aspirations and socioeconomic status, the relationship is much stronger for expectations. The recent literature shows how these are shaped by the adults surrounding them as part of a wider sociocultural context and their horizons for action (Hodkinson and Sparkes, 1993, 1997) within it. Parents and teachers exert a strong influence on which possible selves appear probable to young people. Importantly, these expectations may be an entirely realistic assessment given structural constraints such as local labour market. Markus \& Ruvolo (1989) contend that where a like-to-be self is not deemed as probable, its motivational power will be diminished. As such, it appears that expectations might be a more useful predictor for HE participation than aspirations.

We now turn to empirical data collected as part of a wider project exploring the experiences and attitudes of two generations of practitioner-managers. These individuals have (or have had) a key role by bridging between government policy and chalkface practice, being responsible for conceiving, delivering and evaluating outreach activities. Their conceptualisation of ideas such as 
aspirations and expectations and their beliefs about influencing school attainment is (or has been) directly salient to what activities are offered and to the wider discourse within the sector. Their position near the chalkface also means that they have a privileged perspective on how practices impact on young people through direct involvement with their delivery.

\section{Methodology}

This paper draws on a subset of the findings of a larger mixed methods project ('Assessing Impact and Measuring Success') that examined how perceptions of the purpose and effectiveness of outreach activities has changed over time, focusing on two generations of practitioner-managers. The overarching aim of the project was to identify elements of continuity and change across the two periods (mid/late 2000s and mid 2010s) within the perspectives of those professionals responsible for outreach activities. We were interested in how the participants drew on their professional experiences to explore how they constructed and understood the underlying processes of outreach work and how these fitted into wider discourses of impact, success and value-for-money. We were mainly concerned with their subjective beliefs about effectively influencing young people's decision-making processes, not on what they could specifically evidence from programme evaluations. As such, the study was undertaken within a broadly social realist tradition at the interface between individual constructions and shared professional discourses, bridging policy and practice. More information about the study and its methodology can be found in the project reports (Harrison \& Waller, 2015; Waller et al., 2015).

\section{Design and data collection}

The altered organisational structure, from the nationally-led, regionally-adapted Aimhigher programme to the atomisation across individual HE institutions, meant that different research methods were required within the context of a basic cross-sectional design. The project, which ran from early 2014 to late 2015, therefore comprised two strands:

- Strand 1 involved extended semi-structured telephone interviews with former senior managers within Aimhigher across the nine regional operations and the national organisation. The interviews were shared between the two authors, lasted between 40 and 80 minutes and were audio-recorded.

- Strand 2 involved an online survey of then-current outreach managers with HE institutions using the Bristol Online Survey system. The questionnaire contained both open and closed questions, providing a mix of qualitative and quantitative data, and was designed to take around thirty minutes to complete. All 151 English HE institutions were invited to participate through an e-mail (and two reminders) sent to the main contact for outreach provided by the Office for Fair Access.

The interview schedule and online questionnaire (available on request from the corresponding author) were informed by our previous careers as outreach practitioners and focused around four broad organising themes: (a) the perceived purpose of outreach activities in terms of the specific impacts on young people's knowledge, attitudes or behaviours, (b) conceptualisations of how effective they were and the pathways for this effect to occur, (c) experiences of partnership working with schools and other $\mathrm{HE}$ institutions, and (d) the perceived challenges of evaluating 
outreach activities in a complex social field where there is a lengthy time delay between the activities and HE participation. The data from the third and fourth themes have been reported elsewhere (Harrison and Waller, 2017) and the focus here is on the first and second.

\section{Ethics}

The project was given ethical approach by the host university's relevant ethics committee; participants were guaranteed anonymity and confidentiality, with informed consent secured through an information sheet that was e-mailed in advance and confirmed verbally (Strand 1) or through a tickbox on the online survey (Strand 2).

\section{Sampling and limitations}

Within Strand 1, we were able to contact (by e-mail) and secure the participation of individuals representing all nine regional Aimhigher operations and the national organisation, although some were not in post across the whole period. As such, we had 100 percent coverage. Due to the small numbers, no details are given about the participants to help preserve their anonymity; they are numbered from P1 to P10. Several of the participants were known to us, which may have impacted to some extent on what they were willing to say, but this did not appear to be the case given the open and expansive discussions that took place.

Within Strand 2, we received 57 responses, giving an overall response rate of 38 percent. The response rate was somewhat higher among institutions having university status prior to 1992 (44 percent) than among those gaining university status more recently (37 percent) or colleges (33 percent). This most likely reflects the amount of resource available in the institutions and the relative size of their outreach operations. More broadly, there was a good representation of different sizes, intakes and types of institution relative to the population. While the Strand 2 data was derived from a self-selecting sample, there was no reason to believe that the participants were atypical, except that they may have had higher-than-average interest in the theoretical underpinnings of outreach work. Reasons for non-response reported by those invited included work pressure and survey fatigue.

We are conscious that the self-selecting nature of the Strand 2 sample is a limitation for the study, but we feel that the sample is defensibly representative, insofar as that we could not identify any basis on which it was significantly divergent from the population. Nevertheless, it is possible that the non-respondents may have had very different perspectives and this therefore limits our claims to knowledge. However, the results were consistent with our broader knowledge of the field and there were no challenges to our findings when they were presented to practitioner audiences on several occasions.

\section{Data analysis}

As noted above, we started with specific a priori themes based around our pre-existing knowledge of the field and these were also used as the starting point for analysis; while we allowed space for additional themes to emerge inductively, none did. Both strands were informed by diverse voices 
and we therefore focused on identifying commonalities that represented a broad majority view within each theme, while also recording divergent voices.

The Strand 1 recordings were not transcribed, but were listened to separately by both authors, with extensive notes taken and illustrative quotes extracted. These were then discussed to build an agreed account that respected points of agreement and difference between the ten participants. Within Strand 2, the quantitative data were used to build a descriptive picture of the perspectives held by the sample. The qualitative responses to open questions were then read by both authors and illustrative quotes extracted to provide richness to supplement the basic statistics.

Once the analysis of the individual strands was complete, we then focused on comparing (a) the majority and divergent views within strands, and (b) the majority views between strands. Our aim was to establish a synthesis that, as far as possible, accurately represented the diverse views of the two generations of practitioner-managers and examined whether there had been changes over time, given the changing organisation of outreach and other contextual factors.

Finally, specifically for this paper, we reconsidered the data in the light of the 'possible selves' theoretical lens explored above. This was not part of the original thinking for the wider study, but has more recently come to our attention as a useful tool for making meaning from our data and linking it to the recent literature on aspirations, expectations and attainment. In particular, we looked for evidence of the inadequacy of aspirations alone as an explanatory framework for decisions about higher education, drawing on elements of the accounts where the participants emphasised expectations or attainment - or, indeed, where they did not. We were interested in whether the participants implicitly worked within the like-to-be construction of desirability, or whether they would also integrate ideas around expectations that mark out probable selves; our theoretical lens would predict that these are more likely to motivate current action, for example, to increase attainment.

\section{Findings}

\section{Strand 1: former Aimhigher directors}

The accounts collected from the Strand 1 participants were rich and detailed. Several commented that they enjoyed the opportunity to reflect on the Aimhigher period, especially with the hindsight provided by the intervening period. While some had partly or fully retired, most were still active to some degree within widening participation or related fields, affording them a perspective over time, as well as their direct recollection of their work within Aimhigher.

There was a strong convergence in the ways in which they conceptualised and understood outreach work, albeit with nuance. All the accounts reflected, to a greater or lesser extent, the 'aspiring-raising' brief within the Aimhigher founding documents (e.g. HEFCE, 2004). However, there was variation in the extent to which they felt this work was effective. Some clearly did, but others argued that it was perhaps secondary to a focus on attainment, instead prioritising inputs that might nudge attainment upwards for those young people felt to have the potential for better results with more input: 
'We didn't just bang on about university. I mean, what we did say, is what we're interested in is children sitting their GCSEs - getting GCSEs - and we put a lot of support into that in maths and English in particular, using university students to go into schools to help and so on' (P6).

This recognised a clear imperative about the realities of participation, with or without aspirations being in place:

'If they don't get the qualifications to get into university then it doesn't matter how much they want to get there, it's not going to happen' (P6).

Working with schools, with their own imperatives to improve attainment to satisfy league tables, was therefore a natural alliance, with more attention given to qualification outcomes - especially shifting young people into achieving 'good' passes (at grade C), rather than perhaps stretching the most able (Ball et al., 2012).

Several participants alluded to a belief in the two missions as linked and reinforcing. One spoke about working towards a sudden shift to where a given young person might identify university as a desirable and achievable future:

'What happened in that lightbulb moment that said "Right, I'm going to go home, I'm going to do my homework, I'm going to get my GCSEs, I'm going to get my A Levels and I'm off to university"?' (P2).

In other words, identifying $\mathrm{HE}$ as worthy of working towards was seen as driving greater motivation towards school work and therefore the higher attainment that makes HE achievable.

A stable consensus across the Strand 1 participants was that working with younger age groups was most likely to effect transformational change. Several gave examples of activities with primary schools, where it was felt that children's ideas about their future were more pliable before disadvantage had been 'cemented' (P4) and where it was easier to challenge ingrained expectations derived from parents, teachers and the wider community - another (P2) talked about 'comfort zones' out of which young people needed to be pulled and 'walls' that narrowed their horizons. These activities might, for example, focus on expanding children's understanding of career pathways within familiar work settings like hospitals or construction sites ('try and get the kids talking and thinking about [...] jobs that adults did and one that they might be interested in doing later on', as explained by P1), as well as doing more closely focused work around introducing and normalising HE:

'When I first went into primary schools and you asked questions about HE and who wanted to go to university I would estimate that about $30 \%$ would put their hands up. Towards the end I would go in and I would say it was about $70 \%$. I'm not saying it was only as a result of Aimhigher, but Aimhigher was very instrumental in getting primary schools to encourage talk of university progression' (P7).

It is questionable whether this activity is covered by the term 'aspiration-raising' as it is rather more focused on broadening options and challenging expectations by introducing career and educational pathways that might be unfamiliar within disadvantaged communities, as well as impacting on the school ethos and attitudes of teachers; any gains in aspirations appeared to be 
secondary to these broader goals. The unanimity that this form of early engagement work at primary and lower secondary was very effective at changing children's expectations was counterpointed by regret from several participants who felt that this work had withered back in recent years.

The participant (P2) who talked about 'comfort zones' and 'walls', also reflected on the narrow horizons for action among disadvantaged communities, with a strong focus on the familiar. Another typified these communities as 'disconnected' through intergenerational unemployment and stressed the need to focus on community expectations at least as much as individual aspirations:

'It wasn't even good enough to go and work with some 13-plus kids - a lot of these things that you're dealing with are so deeply embedded that you need to be doing things from the very earliest years in primary school and maybe even before that' (P1).

Within this context, another (P3) talked about the need to 'influence the wider family's appreciation of where the child might be going', within 'a much more rounded sense that education leads somewhere appropriate for every student'. This could lead to a marked change where 'the parents were quite proud, and they would talk about their children being "Aimhigher children"' (P6). Schools were key in this regard, either as a reliable source of factual information or as part of a wider endeavour to persuade parents about the value and achievability of HE for their children:

'We realised from the very start that schools often didn't have a very good dialogue with parents about their children's futures [...] So we did a lot of work persuading schools with our support to talk to parents' (P6).

More broadly, many of the participants reflected on the contrast in ethos between the schools they had worked with. Some were forward-looking, where the mission of the school is to think about the progression of the student beyond the school' (P3), but others were found to have low expectations of their pupils or a rigid focus on their highest-achieving (and most advantaged) pupils. One (P5) felt that activities had helped to raise the aspirations held by teachers about young people, while others framed the change in terms of longstanding expectations:

'Teachers changed markedly over the life course of Aimhigher - at the start they would often shrug their shoulders and say, "What do you expect from kids from round here?", to actually being quite excited by what they children had been able to do' (P10).

However, the participants often reported structural constraints within the schools that acted as a brake in terms of diversifying or supporting the aspirations that the young people did have around HE or future careers:

'We did try to bolster the career guidance and advice, because we felt that in many cases, it wasn't of a terribly high quality [...]. Sometimes they didn't have trained staff - the teachers sometimes weren't trained specialists and the amount of support they could give was very variable' (P6).

In summary, all participants had a strong belief in the value of activities exposing disadvantaged young people to $\mathrm{HE}$. The worlds that they inhabited were constructed as having narrow horizons 
for action (Hodkinson \& Sparkes, 1993, 1997), with a disconnect from education and its role in life chances. The participants generally saw the mainstay of their former role as extending these horizons for action and seeking the 'lightbulb moment' when a young person establishes HE as a possible and desirable future; a like-to-be self. Some, but not all, felt that aspiration-raising was sufficient to motivate young people to improve their attainment. Others saw attainment-raising as a separate (or even the primary) endeavour that constructed whether a young person saw HE as viable - i.e. whether it was a probable self. Some Strand 1 participants reflected on the importance of providing an additional portfolio of activities to challenge expectations - the young person's (often from a young age), but significantly also those of the community, the teachers and the parents; these were seen as the source of transformational change, but several participants lamented their decline since the end of Aimhigher. These expectations play an important role in the relative likelihoods that young people attach to their possible selves.

\section{Strand 2: current widening participation managers}

Within a much longer questionnaire (see Harrison \& Waller, 2015), participants in Strand 2 were asked to indicate how successful they felt their institution had been at impacting on various outcomes with respect to widening participation. Four answers were permissible (very successful, quite successful, rather unsuccessful and not applicable) and the results are shown in Figure 1.

Figure 1: perceived institutional success at influencing young people $(n=57)$

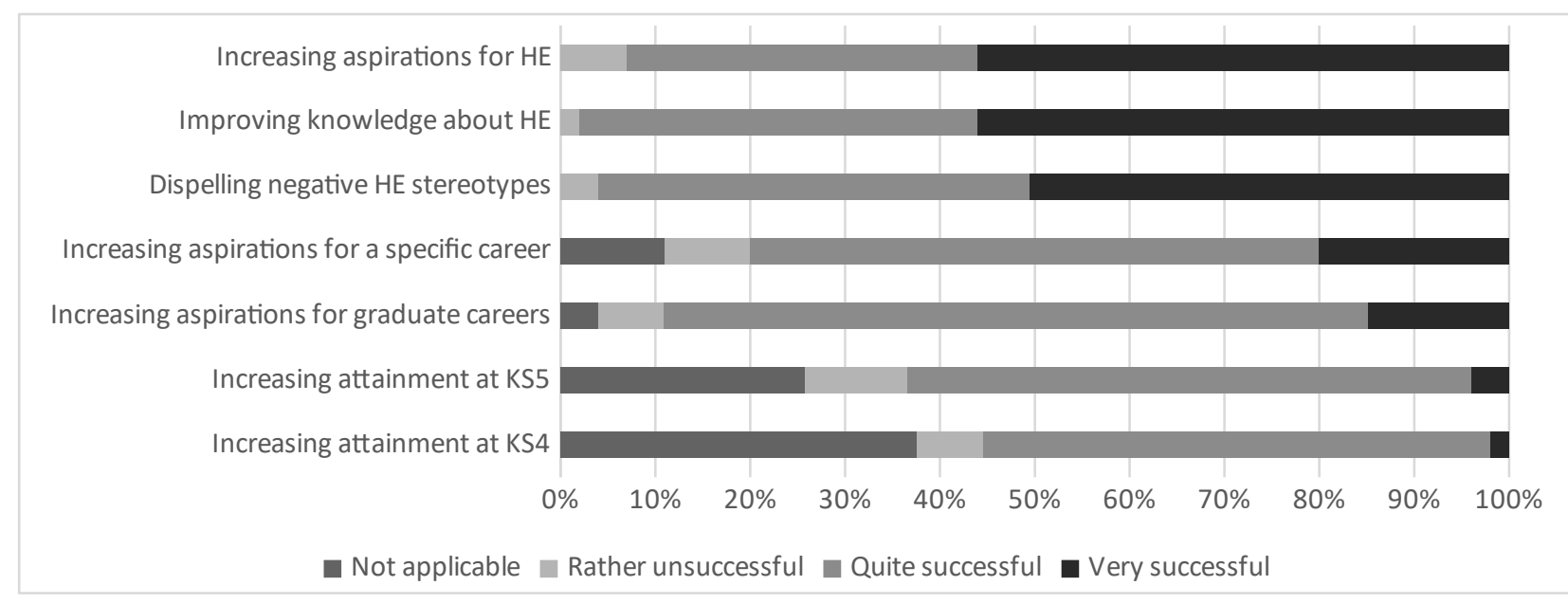

In general, the respondents were very confident in their institution's ability to raise aspirations, improve knowledge and dispel negative stereotypes. Confidence declined markedly around aspirations for careers, but it was lower still around increasing attainment, either at Key Stage 4 or 5. While just over half felt that they had some positive success, the numbers feeling that they had been 'very successful' were tiny. Across the outcomes, respondents from HE colleges were generally less confident in their success than those from universities. Perhaps most interestingly, 26 percent answered 'not applicable' with respect to attainment at Key Stage 5 and 38 percent at Key Stage 4 - in other words, they saw attainment as outside the purview of their institution's outreach work. 
Respondents were also asked to specify which of their institutions' activities they felt were most successful across four outcomes: demystifying $\mathrm{HE}$, raising aspirations for $\mathrm{HE}$, increasing attainment and increasing $\mathrm{HE}$ applications. A wide range of activities were described by the respondents and these were grouped appropriately. Those groups that garnered at least five responses are listed in Table 1.

Table 1: activities perceived as most successful across four outcomes [ $n=57]$

\begin{tabular}{|c|c|c|c|}
\hline Demystifying HE & $\begin{array}{l}\text { Raising aspirations } \\
\text { for } \mathrm{HE}\end{array}$ & $\begin{array}{l}\text { Raising prospective } \\
\text { students' attainment }\end{array}$ & $\begin{array}{l}\text { Increasing } \\
\text { applications to } \mathrm{HE}\end{array}$ \\
\hline $\begin{array}{l}\text { Campus visits / taster } \\
\text { days (20) }\end{array}$ & $\begin{array}{l}\text { Summer schools / taster } \\
\text { weeks (14) }\end{array}$ & $\begin{array}{l}\text { Subject enrichment / } \\
\text { masterclasses / revision } \\
\text { sessions (15) }\end{array}$ & $\begin{array}{l}\text { Summer schools / taster } \\
\text { weeks (12) }\end{array}$ \\
\hline $\begin{array}{l}\text { School visits / } \\
\text { information } \\
\text { presentations (13) }\end{array}$ & $\begin{array}{l}\text { Campus visits / taster } \\
\text { days (13) }\end{array}$ & $\begin{array}{l}\text { Student mentoring / } \\
\text { tutoring (15) }\end{array}$ & $\begin{array}{l}\text { School visits / } \\
\text { information } \\
\text { presentations (11) }\end{array}$ \\
\hline $\begin{array}{l}\text { Summer schools / taster } \\
\text { weeks (9) }\end{array}$ & $\begin{array}{l}\text { School visits / } \\
\text { information } \\
\text { presentations (12) }\end{array}$ & $\begin{array}{l}\text { Compact schemes / } \\
\text { ongoing sixth form } \\
\text { engagement (6) }\end{array}$ & $\begin{array}{l}\text { Campus visits / taster } \\
\text { days (10) }\end{array}$ \\
\hline $\begin{array}{l}\text { Interaction with student } \\
\text { ambassadors (9) }\end{array}$ & $\begin{array}{l}\text { Interaction with student } \\
\text { ambassadors (7) }\end{array}$ & & $\begin{array}{l}\text { Compact schemes / } \\
\text { ongoing sixth form } \\
\text { engagement (7) }\end{array}$ \\
\hline $\begin{array}{l}\text { Student mentoring / } \\
\text { tutoring (5) }\end{array}$ & $\begin{array}{l}\text { Engagement with } \\
\text { primary schools / } \\
\text { parents (5) }\end{array}$ & & $\begin{array}{l}\text { Student mentoring / } \\
\text { tutoring (7) }\end{array}$ \\
\hline
\end{tabular}

Other activities mentioned: open days; providing Foundation Degree programmes; shadowing students; financial support to FE students; after-school clubs; engagement with parents; signposting community centres and third sector programmes; pastoral support; links with industry; alumni talks; social media; making reduced offers.

There was a marked lack of consensus among practitioner-managers as to what the most effective activities were for any of the four outcomes. However, there was a significant commonality between the answers for raising aspirations and those for increasing applications, suggesting that the respondents saw these outcomes as being closely linked.

Conversely, the activities seen as most successful in raising attainment were generally quite distinct. They tended to involve close pedagogic contact between young people and HE staff or students, supplementing teaching in schools through curriculum enhancement activities, revision workshops, after-school clubs or one-to-one tutoring. In keeping with Figure 1, many participants remarked that they did not seek to influence attainment.

It is also notable that engagement with primary schools and parents were mentioned by fewer than 10 percent of respondents, while careers advice/guidance activities were almost completely 
absent. It was unclear whether this was because they were felt to be ineffective or that they were simply not part of the portfolio of activities offered. Most commonly, the activities described were focused on young people aged over 16, although there were a few examples of work with younger groups, including structured programmes of interventions spanning multiple years.

Finally, the Strand 2 respondents were asked about the process of evaluating their outreach activities. The majority felt that forms of longitudinal tracking generated the most reliable evidence for effectiveness as it enabled changes in a young person to be monitored through their involvement in multiple activities. However, this was often at odds with managerial and regulatory imperatives. For example, one described the conflict between the 'pressure to deliver evaluation results quickly when in practice the process [of effecting change in a young person] takes years', while another identified the challenge of 'assessing the impact of individual activities when we know that the impact of outreach activities are culminative'. Others reflected on perceived need to offer activities that were demonstrably successful in ways that were directly causal, could be quantified and that would provide a return-on-investment in terms of applicants. This was a double imperative for (especially lower-status) institutions, who needed to ensure their recruitment remained buoyant in a competitive market and to recruit sufficient disadvantaged students to escape censure from OFFA.

In this environment, it is perhaps unsurprising that many of the activities valued by the Strand 1 participants had declined. As noted earlier, few Strand 2 respondents mentioned work with primary schools, with its long lead-time between intervention and application, and fewer still engaged directly with key adult influencers like parents or teachers, which the Strand 1 participants viewed as important for challenging expectations. The transformative activities sought by the Strand 1 participants have, to some extent, given way to a more instrumental set of activities that are readily measured and potentially line up with marketing activities; 'what gets measured gets done' (Behn, 2003, p.599).

In summary, the practitioner-managers in Strand 2 painted a somewhat different picture to those in Strand 1. While they remained comfortable working within a discourse of aspirations, which was seen as closely linked to applications, they were much less sure as to their role in raising attainment or challenging expectations. Despite the vital importance of attainment to $\mathrm{HE}$ participation (Crawford, 2014; Crawford \& Greaves, 2015), around a third - across all institutional types - felt it was entirely outside their remit. Some institutions reported well-founded practices, but their confidence in their efficacy (and their ability to prove that efficacy) tended to be low. Activities to directly challenge adult expectations were largely absent from the accounts. Thus, the Strand 2 data suggests that the focus of outreach activities had contracted back to forming HE as a like-to-be self, with relatively little attention to elaborating this or making it seem probable. This appeared to due to reductionist pressures to offer activities that offered quick and supposedly guaranteed results for individual institutions, in contrast to the sustained long-term activity that was felt to be most effective in both strands.

\section{Discussion}

Aspirations exist within the realm of shared human existence - the desire for a better future than the present. What this might comprise is clearly individual (Markus \& Nurius, 1986), but may draw on concepts like happiness, comfort, status and/or societal contribution. Discourses around 'low aspirations' are hard to understand: why would people not seek a desirable future, in the terms 
that they understand it? Indeed, recent evidence is clear that young people across all social groups generally have high educational and career aspirations (Archer et al., 2014; Baker et al., 2014; St Clair et al., 2013).

Furthermore, previous studies demonstrate that fewer young people expect to progress to HE than aspire to do so. Expectations are a better predictor of outcomes (Croll \& Attwood, 2013), while Khattab (2015) estimates that 25 percent of young people have high aspirations but low expectations, and these are particularly found among lower socioeconomic groups (Boxer et al., 2011). Perhaps expectations need policy attention rather than aspirations - several Strand 1 participants felt this was the case based on their extensive experience in the field.

Unlike aspirations, expectations include a complex set of internal and external judgements about the future - e.g. do I have the potential, will I work hard enough, will my work be rewarded, will there be a place for me and will I be able to take it up? The differences identified by Croll \& Attwood (2013) and Khattab (2015) reflect the young people's assessment of both their desire to progress, but also how likely they think it is that circumstances will permit them to do so. As discussed by several of the Strand 1 participants, expectations are forged in a web of influences including their family, their community and their understanding of - and beliefs about - the structural constraints of the education system and the labour market (Hodkinson \& Sparkes, 1993, 1997). While Kintrea et al. (2015, p.667) argue that 'young people's aspirations are shaped by a complex range of influences, including their own cognitions, family and peer influences, influences from the wider society and the media, as well as the place in which they live', this is even more marked for expectations.

We can use the lens provided by Markus \& Nurius (1986) to explore the data from Strands 1 and 2 further. At the most basic level, the aspiration-raising activities that formed the mainstay of work in both strands can be seen as an attempt to establish 'life as a graduate' first as a possible, and then as a like-to-be, self for the young people - the 'lightbulb moment'. The Strand 1 accounts also often reflected a wider mission to expand the pool of possible lives more generally through career-focused work; this was largely absent within Strand 2.

However, Markus \& Nurius (1986) draw a clear distinction between like-to-be and probable future selves, the latter being grounded in expectations rather than merely aspirations. These assessments of probability might be influenced, inter alia, by limited knowledge about graduate jobs as they are less likely to come into contact with people holding them, the prioritising of careers that meet normative pressures around appropriate gender roles or a belief that hard work is futile in a community where few graduate jobs are available (St Clair et al., 2013) and where a history of 'disconnection' sees aspirations often go unfulfilled (Raphael Reed et al., 2007). Vitally, a like-to-be self that is not also considered a probable self is argued to be unlikely to spur action in the short-term. There were clear signs of this thinking within Strand 1, but very little in Strand 2 .

For example, most of the Strand 1 participants identified parents and teachers as key influencers. Parents might, for example, provide normative cues about 'respectable' forms of future work and their own beliefs about the role of education. Similarly, teachers might harbour their own opinions about the most 'appropriate' pathways for young people and have outdated information or stereotyped views about their likelihood of success (Rubie-Davies et al., 2015). Parents and teachers can thus have an important role in helping young people to elaborate their possible selves (Archer et al., 2014; Baker et al., 2014), as well as shaping the young person's assessment of the likelihood of realising possible and like-to-be selves (Fuller, 2014; Winterton \& Irwin, 2012). 
The Strand 1 participants in our study had a strong sense that engagement with parents and teachers was a vital component of outreach activity, seeing the social milieu as vital to shaping young people's own expectations about their future. However, this emphasis was largely absent from the Strand 2 accounts, which were predominantly focused on young people alone.

Finally, the Strand 1 and 2 accounts both speak for an equivocal stance on attainment-raising. Within both strands, there was a mix of those who saw attainment as outside the scope of outreach, those who saw attainment as being driven by aspirations and those who saw attainment-raising as a separate sphere of activity. The lens of possible selves would envisage attainment as playing two roles within HE participation. Firstly, attainment makes those possible selves predicated on qualifications appear more probable (Gorard et al., 2012). Secondly, motivation for school work will be legitimised and given meaning by the pursuit of a like-to-be self. This relationship is challenged by Cummins et al. (2012) and Gorard et al. (2012), but it may be that the like-to-be self must also be viewed as probable before it has a role in motivation and attainment.

In summary, the policy discourse around aspirations therefore potentially makes several important errors. Firstly, it risks assuming that futures viewed as desirable by practitioners are viewed similarly by young people - that when HE becomes a possible self, it also becomes a like-to-be self. Secondly, it risks failing to elaborate the role of $\mathrm{HE}$ within possible selves, such that being a student is presented as an end in itself - this may be more or less desirable to the young person. Thirdly, it neglects the role of perceived likelihood that defines probable selves. Finally, it risks assuming that the existence of possible selves that are predicated on $\mathrm{HE}$ is sufficient to motivate young people - it may be more likely that this only occurs when the self is both desirable and probable.

\section{An alternative policy agenda}

We therefore argue that the challenge for policy and practice is to help young people (a) to elaborate a rich pool of possible selves, (b) to understand how their like-to-be self might be met through $\mathrm{HE}$, and (c) to also see this as probable self. To achieve this, a shift of attention away from aspiration-raising and towards expectations is needed - this is also likely to influence attainment more directly. A full exposition of the activities this might entail is beyond the scope of this paper. However, we will briefly outline three broad approaches that are likely to be useful.

The first is to work with younger groups of children while their expectations are still forming and when a more expansive pool of possible selves can be developed. In particular, universities have well-founded careers services which could easily have some of their attention shifted to outreach work to raise awareness of a wide range of graduate careers, the relevance of $\mathrm{HE}$ and the importance of decisions about qualifications (Archer et al., 2014). If the like-to-be self is to be realised, young people need help to articulate it clearly alongside high-quality guidance to understand the steps required. Archer et al.'s (2014) concept of diversifying and informing aspirations is potentially helpful here, as distinct from raising them, while Cummings et al. (2012) identify an imperative to keep aspirations 'on track' by making them seem achievable. Also, as major employers, universities can offer high-quality work experience placements or lever in opportunities from organisations with which they are partnered (Waller et al., 2015). Importantly, young people need to have a clear sense that hard work at school will bring future reward (Fuller, 2012) rather than the disconnect reported by Raphael Reed et al. (2007). 
The second is to engage more directly with parents and other community influencers to challenge the expectations they hold for young people. Viewing communities as a 'unit of action' in their own right was often part of the Aimhigher ethos (and evident in the wider Strand 1 data), but this has fallen away as outreach efforts have been dispersed - it remains to be seen whether the NNCOs and NCOP have reversed this trend with their renewed focus on collaboration. Involving parents in re-visioning their children's future is likely to reinforce key messages provided through outreach work, as well as impacting positively on attainment (Cummings et al., 2012; Gorard \& See, 2013).

The third is to focus more attention on teachers - there is little Strand 2 data to suggest that this is currently a priority for institutions. Thomas, Bland and Duckworth (2012) argue both that teachers are key to widening participation efforts and that universities have an important role in working with them, particularly through their education departments. Trainee teachers can advocate for $\mathrm{HE}$ within schools, while alumni networks and in-service training can be used to challenge stereotyped expectations and ensure that knowledge of HE is up-to-date - a similar argument could also be made around social work and other disciplines engaged in disadvantaged communities. Education departments are also well-placed to assist in terms of developing theorygrounded attainment-raising interventions across the primary and early secondary phases.

Indeed, outreach activity in institutions has tended to become divorced from academic departments, being more commonly located within the recruitment and admissions function in recent years - this is evidenced by the job titles of the people responding to the Strand 2 survey. This may signal the way it is viewed by senior managers, rather than simply being an act of administrative convenience. Academic departments do routinely contribute to activities to widen participation, but it is less common that they contribute their research expertise. This is fundamentally curious. A key role of the contemporary university is to develop solutions to social problems and universities have a wealth of relevant expertise housed within departments of education, sociology, psychology, and others which could be brought to bear.

\section{Conclusion}

This paper has engaged with long-standing critiques of the deficit discourse around raising aspirations among disadvantaged young people. It has acknowledged recent large-scale studies that have found no shortage of aspirations and added new data comprising the experiences and conceptualisations of two generations of practitioner-managers.

These accounts have provided several insights. Firstly, the language of aspiration-raising continues to permeate the field - it is where practitioner-managers appear comfortable and where they feel their institutions are successful. Secondly, there is little confidence that institutional efforts to raise attainment are successful, with a common reliance on raising aspirations to improve school results. Thirdly, there has been a falling away of activities with more potential for social transformation, in favour of those which have tangible short-term measures of 'success' and a presumed causal relationship with recruitment outcomes. The lost activities include inspirational work with primary schools, work to challenge normative expectations among parents and teachers, work to widen career options and the provision of high-quality guidance; these activities were valued highly by the previous generation of practitioner-managers. 
We have also argued that the 'possible selves' lens advanced by Markus \& Nurius (1986) is a useful one for rigorously distinguishing between futures that young people aspire to have and those that they expect to have, especially when combined with the sociocultural perspective provided by 'horizons for action' (Hodkinson and Sparkes, 1993, 1997). While the context of this paper has been England, this theoretical lens is likely to have a wider application.

Finally, we are keenly aware of the wider debates around instrumentalism and credentialism in education and we need clarify that this is not a call to place more pressure to succeed on already overloaded children. What we are advocating is a policy and practice shift that addresses inequalities earlier in their lives, engages with the adults surrounding young people, provides advice when it is needed and does not perpetuate the classed myth of low aspirations. 


\section{References}

Archer, L. (2007) Diversity, equality and higher education: a critical reflection on the ab/uses of equity discourse within widening participation, Teaching in Higher Education, 12(5-6), 635653.

Archer, L., DeWitt, J. \& Wong, B. (2014) spheres of influence: what shapes young people's aspirations at age $12 / 13$ and what are the implications for education policy? Journal of Education Policy, 29(1), 58-85.

Archer, M. 2007. Making our way through the world: human reflexivity and social mobility (Cambridge, Cambridge University Press).

Baker, W., Sammons, P., Siraj-Blatchford, I., Sylva, K., Melhuish, E.C. \& Taggart, B. (2014) Aspirations, education and inequality in England: insights from the effective provision of preschool, primary and secondary education project, Oxford Review of Education, 40(5), 525-542.

Ball, S.J., Maguire, M., Braun, A., Perryman, J. \& Hoskins, K. (2012) Assessment technologies in schools: 'deliverology' and the 'play of dominations', Research Papers in Education, 27(5), 513533.

Bathmaker, A.-M., Ingram, N., Abrahams, J., Hoare, A., Waller, R. \& Bradley, H. (2016) Higher education, social class and social mobility: the degree generation (London, Palgrave MacMillan).

Behn, R.D. (2003) Why measure performance? Different purposes require different measures. Public Administration Review, 63(5), 586-606.

Bourdieu, P. (1984) Distinction: A social critique of the judgement of taste (London, Routledge and Kegan Paul).

Boxer, P., Goldstein, S.E., DeLorenzo, T., Savoy, S. \& Mercado, I. (2011) Educational aspirationexpectation discrepancies: relation to socioeconomic and academic risk-related factors, Journal of Adolescence, 34(4), 609-617.

Chevalier, A., Gibbons, S., Thorpe, A., Snell, M. \& Hoskins, S. (2009) Students' academic selfperception, Economics of Education Review, 28(6), 716-727.

Chilosi, D., Noble, M., Broadhead, P. \& Wilkinson, M. (2010) Measuring the effect of Aimhigher on schooling attainment and higher education applications and entries, Journal of Further and Higher Education, 34(1), 1-10.

Chowdry, H., Crawford, C. \& Goodman, A. (2010) Explaining the socioeconomic gradient in child outcomes during the secondary school years: evidence from the longitudinal study of young people in England (London, Institute for Fiscal Studies).

Coleman, R., \& Bekhradnia, B. (2011) Higher education supply and demand to 2020 (Oxford, Higher Education Policy Institute).

Crawford, C. (2014) The link between secondary school characteristics and university participation and outcomes (London, Department for Education).

Crawford, C. \& Greaves, E. (2015) Socio-economic, ethnic and gender differences in HE participation (London, Institute for Fiscal Studies).

Croll, P. \& Attwood, G. (2013) Participation in higher education: aspirations, attainment and social background, British Journal of Educational Studies, 61(2), 187-202.

Cummings, C., Laing, K., Law, J., McLaughlin, J., Papps, I., Todd, L. \& Woolner, P. (2012) Can changing aspirations and attitudes impact on educational attainment? A review of interventions (York, Joseph Rowntree Foundation).

Department for Business, Innovation and Skills (2014) National strategy for access and student success in higher education (London, DBIS).

Department for Education (2016) Higher education: success as a knowledge economy (London, DFE). 
Department for Education (2017) Widening participation in higher education: 2017 (London, DFE). Department for Education and Employment (2000) The excellence challenge (London, DFEE). Department for Education and Skills (2003a) The future of higher education (Norwich, HMSO).

Department for Education and Skills (2003b) Widening participation in higher education (London, DfES).

Department for Education and Skills (2006) Widening participation in higher education (London, DfES).

Donnelly, M. (2015) Progressing to university: hidden messages at two state schools, British Educational Research Journal, 41(1), 85-101.

Doyle, M. \& Griffin, M. (2012) Raised aspirations and attainment? A review of the impact of Aimhigher (2004-2011) on widening participation in higher education in England, London Review of Education, 10(1), 75-88.

Fuller, C. (2014) Social capital and the role of trust in aspirations for higher education, Educational Review, 66(2), 131-147.

Giddens, A. (1991) Modernity and self-identity: self and society in the late modern age. (Cambridge, Polity Press).

Goodman, A. \& Gregg, P. (2010) Poorer children's educational attainment: how important are attitudes and behaviour? (York, Joseph Rowntree Foundation).

Gorard, S. \& See, B.H. (2013) Overcoming disadvantage in education (Abingdon, Routledge).

Gorard, S., See, B.H. \& Davies, P. (2012) The impact of attitudes and aspirations on educational attainment and participation (York, Joseph Rowntree Foundation).

Green, F., Parsons, S., Sullivan, A. \& Wiggins, R. (in press) Dreaming big? Self-valuations, aspirations, networks and the private-school earnings premium. Awaiting publication in Cambridge Journal of Economics, doi: 10.1093/cje/bex023.

Hardgrove, A., Rootham, E. \& McDowell, L. (2015) Possible selves in a precarious labour market: Youth, imagined future and transitions to work in the UK, Geoforum, 60, 163-171.

Harrison, N. (2012) The mismeasure of participation: how choosing the 'wrong' statistic helped seal the fate of Aimhigher, Higher Education Review, 45(1), 30-61.

Harrison, N. (forthcoming) Conceptualising higher education access through the lens of 'possible selves' - a new framework to inform policy and practice

Harrison, N. \& Waller, R. (2015) The evaluation of widening participation activities in higher education: a survey of institutional leaders in England (Bristol: University of the West of England).

Harrison, N. \& Waller, R. (2017) Success and impact in widening participation: what works and how do we know? Higher Education Policy, 30(2), 141-160.

Henderson, H., Stevenson, J. \& Bathmaker, A.-M. (forthcoming) Possible selves and higher education: new interdisciplinary insights (Abingdon, Routledge).

Higher Education Funding Council for England (2004) Aimhigher: guidance notes for integration (Bristol, HEFCE).

Higher Education Funding Council for England (2005) Young participation in higher education (Bristol, HEFCE).

Higher Education Funding Council for England (2014) Guidance on National Networks for Collaborative Outreach (Bristol, HEFCE).

Higher Education Funding Council for England (2016) National Collaborative Outreach Programme: invitation to submit proposals for funding (Bristol, HEFCE).

Hodkinson, P. \& Sparkes, A.C. (1993) Young people's career choices and careers guidance action planning: a case-study of training credits in action, British Journal of Guidance and Counselling, 21(3), 246-261. 
Hodkinson, P. \& Sparkes, A.C. (1997) Careership: a sociological theory of career decision making, British Journal of Sociology of Education, 18(1), 29-44.

Jones, R. \& Thomas, L. (2005) The 2003 UK Government higher education White Paper: a critical assessment of its implications for the access and widening participation agenda, Journal of Education Policy, 20(5), 615-630.

Kahneman, D. (2003) Maps of bounded rationality: psychology of behavioural economics. American Economic Review, 93(5), 1449-1475.

Khattab, N. (2015) Students' aspirations, expectations and school achievement: what really matters? British Educational Research Journal, 41(5), 731-748.

Kintrea, K., St Clair, R. \& Houston, M. (2015) Shaped by place? Young people's aspirations in disadvantaged neighbourhoods, Journal of Youth Studies, 18(5), 666-684.

Kirk, C.M., Lewis-Moss, R.K., Nilsen, C. \& Colvin, D.Q. (2011) The role of parent expectations on adolescent educational aspirations, Educational Studies, 37(1), 89-99.

Leathwood, C. \& O'Connell, P. (2003) 'It's a struggle': the construction of the 'new student' in higher education, Journal of Education Policy, 18(6), 597-615.

Leondari, A. (2007) Future time perspective, possible selves, and academic achievement. New Directions for Adult and Continuing Education, 117, 17-26.

Leondari, A., Syngollitou, E. \& Kiosseoglou, G. (1998) Academic achievement, motivation and future selves. Educational Studies, 24(2), 153-163.

Lupton, R. (2005) Social justice and school improvement: improving the quality of schooling in the poorest neighbourhoods, British Educational Research Journal, 31(5), 589-604.

Markus, H. \& Nurius, P. (1986) Possible selves, American Psychologist, 41(9), 954-969.

Markus, H. \& Nurius, P. (1987) Possible selves: the interface between motivation and the selfconcept, in: K. Yardley \& T. Honess (Eds) Self and identity: Psychosocial perspectives (Oxford: John Wiley \& Sons).

Markus, H. \& Ruvolo, A. (1989) Possible selves: personalized representations of goals, in: L.A. Pervin (Ed) Goal concepts in personality and social psychology (Hillsdale, Lawrence Erlbaum).

Moore, J. \& Dunworth, F. (2011) Review of evidence from Aimhigher area partnerships of the impact of Aimhigher (Bristol, Aimhigher/Higher Education Funding Council for England).

National Committee of Inquiry into Higher Education (1997) Higher education in the learning society (Norwich, HMSO).

Nielsen, K. (2015) 'Fake it 'til you make it': why community college students' aspirations 'hold steady', Sociology of Education, 88(4), 265-283.

Office for Fair Access (2016) Outcomes of access agreement monitoring for 2014-15 (Bristol, OFFA).

Oyserman, D., Brickman, D. \& Rhodes, M. (2007) School success, possible selves, and parent school involvement, Family Relations, 56(5), 479-489.

Oyserman, D., Terry, K. \& Bybee, D. (2002) A possible selves intervention to enhance school involvement, Journal of Adolescence, 25, 313-326.Papafilippou, V. \& Bentley, L. (2017) Gendered transitions, career identities and possible selves: the case of engineering graduates, Journal of Education and Work, 30(8), 827-839.

Raphael Reed, L., Gates, P. \& Last, K. (2007) Young participation in higher education in the parliamentary constituencies of Birmingham Hodge Hill, Bristol South, Nottingham North and Sheffield Brightside (Bristol, University of the West of England).

Reay, D., Crozier, G. \& Clayton, J. (2009) Strangers in paradise? Working-class students in elite universities, Sociology, 43(6), 1103-1121.

Rubie-Davies, C.M., Peterson, E.R., Sibley, C.G. \& Rosenthal, R. (2015) A teacher expectation intervention: modelling the practices of high expectation teachers, Contemporary Educational Psychology, 40, 72-85. 
Smyth, E. \& Banks, J. (2012) 'There was never really any question of anything else': young people's agency, institutional habitus and the transition to higher education, British Journal of Sociology of Education, 33(2), 263-281.

St Clair, R., Kintrea, K. \& Houston, M. (2013) Silver bullet or red herring? New evidence on the place of aspirations in education, Oxford Review of Education, 39(6), 719-738.

Stevenson, J. \& Clegg, S. (2011) Possible selves: students orientating themselves towards the future through extracurricular activity, British Educational Research Journal, 37(2), 231-246.

Thomas, L., Bland, S. \& Duckworth, V. (2012) Teachers as advocates for widening participation, Widening Participation and Lifelong Learning, 14(2), 40-58.

Waller, R., Harrison, N., Hatt, S. \& Chudry, F. (2014) Undergraduates' memories of school-based work experience and the role of social class in placement choices in the UK, Journal of Education and Work, 27(3), 323-349.

Waller, R., Harrison, N. \& Last, K. (2015) Building a culture of participation: interviews with the former directors of the national Aimhigher programme (Bristol: University of the West of England).

Winterton, M.T. \& Irwin, S. (2012) Teenage expectations of going to university: the ebb and flow of influences from 14 to 18, Journal of Youth Studies, 15(7), 858-874.

Woodrow, M., Lee, M.F., McGrane, J., Osborne, B., Pudner, H. and Trotman, C. (1998) From elitism to inclusion: good practice in widening access to higher education (London: Committee of Vice-Chancellors and Principals). 